\title{
Energy as a multidisciplinary concept in K-12 education - a case study
}

\author{
Mats Braskén ${ }^{1}$ and Ray Pörn² \\ ${ }^{1}$ Faculty of Education and Welfare Studies, Åbo Akademi University, Vaasa, Finland \\ ${ }^{2}$ Faculty of Technology and Seafaring, Novia University of Applied Sciences, Vaasa, Finland
}

Although one of key ideas behind the introduction of STEM (or STEAM) as a unifying concept, is to emphasize the interdisciplinary character of many real world problems, there is a non-trivial educational challenge in exceeding existing subject boundaries and implementing multidisciplinary activities into the classroom. The present case study covers the design, implementation and evaluation of a multidisciplinary unit in a Finnish lower secondary school, grade 9. The entire multidisciplinary unit was organized around the central concept of energy, and the present study focuses on an activity within that unit that explored how energy can be used to analyze both living and non-living systems. Evaluation of the activity was done with pre and post student questionnaires, analyzing the students' written poster presentations and focus group interviews done with a voluntary group of students after the whole unit. The aim of the study was to explore how students understand the multidisciplinary character of the energy concept. Our results show both challenges and possible gains of working in a multidisciplinary way. However, to succeed serious thought has to be invested in both identifying core concepts that gain by being analyzed in an interdisciplinary way, and in the design of appropriate learning activities around these core concepts. Our study is as an effort in this direction.
Article Details

LUMAT General Issue Vol 9 No 1 (2021), 77-99

Received 31 August 2020 Accepted 2 February 2021 Published 19 February 2021

Pages: 23

References: 18

Correspondence:

mbrasken@abo.fi

https://doi.org/10.31129/ LUMAT.9.1.1402

Keywords: multidisciplinary learning, interdisciplinary learning, STEM, K-12 education, energy concept

\section{Introduction}

To meet the societal and educational challenges of the future, a set of so-called 21stcentury skills have been identified as vital for students to thrive in a rapidly changing, digital society. As a direct response to this trend, educational policy developers and schools in many countries have tried to formulate goals in line with the 21st century skills (e.g. McPhail, 2018; Voogt \& Roblin, 2012). In some countries the answer to the question of how to design a curriculum that better supports the development of these skills, is a push towards an increased integration among different school subjects and disciplines, or towards an increased interdisciplinarity (Czerniak \& Johnson, 2014). The underlying idea is that by emphasizing the interdisciplinary features, of until now mostly STEM related subjects, the curriculum will better reflect the real world and therefore provide students with a more authentic context in which learning can take 
place. This will, according to the proponents of interdisciplinarity, not only sharpen students' critical thinking and problem-solving skills, but also have a positive effect on student interest and motivation for school (Czerniak \& Johnson, 2014). The concept of energy, which is the focus of the present study, is by its very nature interdisciplinary.

The new Finnish curriculum formulates a set of transversal (generic) competences, similar to the set of 21st century skills mentioned above, as a way of meeting future challenges (Finnish National Board of Education [FNBE], 2016). The learning objectives of these competences include: thinking and learning to learn; cultural competence, interaction and self-expression; taking care of oneself and managing daily life; multiliteracy; information and communication technology (ICT) competence; working life competence and entrepreneurship; and participation, involvement and building a sustainable future (FNBE, 2016). One key idea in the new national core curriculum is to encourage closer cooperation between different school subjects, what in the curriculum documents is referred to as a multidisciplinary way of working. The use of the term "multidisciplinary" in this context is not one universally adopted internationally. We will use the term multidisciplinary in this study. For a deeper discussion of how the concept of multidisciplinarity is related to interdisciplinarity see (Braskén et al., 2019). The stated goal of the multidisciplinary approach is to support the development of the transversal (generic) competences and provide students with a more realistic context in which learning can take place. By offering students an opportunity to both identify, formulate, and investigate problems that are of interest to both them and their peers, the hope is that a more positive attitude towards both school and school subjects will result.

These are the hopes and ambitions put forward in curriculum documents, but how does one as a school, teacher and subject expert, turn the ideas of multidisciplinarity into actual practice? The present case study is an example of an attempt to do this. The context of our study is a set of STEM related activities, spanning three 60-minute long sessions in total, that were part of a larger multidisciplinary unit in grade 9 with the overall theme of "Energy". The entire multidisciplinary unit consisted of two weekly 6o-minute long sessions for a total of seven weeks and all students in grade 9 participated in the unit. In spring 2017, 44 students participated in the unit. The content related goal of the unit was to give the students a broader understanding of the concept of energy, by exploring the energy concept through the lens of different subjects (science, technology and social sciences). 
The teachers involved in the unit, representing the subjects, mathematics, physics, chemistry and biology, developed the majority of the activities making up the multidisciplinary energy unit. However, the activity that is the focus of the present case study was developed in collaboration with the researchers. This activity is described in detail in Appendix A (translated from Swedish) and was designed to let students explore the relevance of the energy concept to understanding the human body. This activity will hereafter be designated "the energy-body lab". Our goal as researchers in developing the energy-body lab, was to engage the students in a set of three, short explorations designed to highlight how the concept of energy can be used to analyze both physical (non-living) and biological (living) systems. By exposing students to the multidisciplinary character of the energy concept, the ambition was that they would gain a deeper understanding of the concept of energy, and specifically as it relates to biological systems and their own body. It should be noted that no other activity in the energy unit emphasized this connection. Out of the 44 students participating in the entire multidisciplinary unit, eight students chose to participate in the energy-body lab.

To probe the participating students' attitudes towards and perceptions of the whole unit, all students were given a questionnaire before and after the unit. The questionnaire was designed to probe possible shifts in their perceived importance of the energy concept in general, and how they perceived the multidisciplinary aspects of the energy concept. Two of the students participating in the energy lab were also interviewed after the whole unit, recording their experiences of the unit. Finally, the energy-body lab posters produced by the students, and documenting their lab results, were also gathered and analyzed. By using this data and these artifacts, we strived to answer the following research question:

Research question: How is the students' understanding of the multidisciplinary character of the energy concept, as relating to living and nonliving systems, visible in their responses, presentations and discussions? 


\section{Theoretical framework}

One of the motivations for integrating different subjects into a multidisciplinary unit is that some key concepts in science and technology are by their very nature interdisciplinary. Energy is one such concept and it is identified as one of seven so called crosscutting concepts in the Next Generation Science Standards (NRC, 2012). From a student perspective, a solid understanding of the concept of energy is deemed as foundational for being able to understand and participate in discussions concerning such vital topics as sustainability, climate change and possible future energy solutions (e.g. Nordine, 2016). The choice made by the teachers of focusing on energy as a central theme for the multidisciplinary unit is thus theoretically well motivated. However, the concept of energy is both a deep and difficult one. Much research has been done on both students' misconceptions of the concept of energy and how and at what age different aspects of energy should best be thought (Duit, 2014). Adding to this challenge is the fact that different disciplines use the term "energy" somewhat differently. While physicists view energy primarily as a quantity that is conserved in interactions, a biologist may focus more on how energy is transferred across system boundaries and an economist on it being a scarce resource. To add to this challenge, the word "energy" has various (non-scientific) uses in everyday language. We speak of our body "using" energy from food to keep us alive, that we are exhausted or "out of energy", and that the batteries of our cellphone are "empty". All these everyday uses depict energy as a material substance that can be stored in batteries, poured into us when we drink a sugary drink and that is forever lost when the cars gasoline tank is empty (Millar, 2005). In principle, there should be no problem with words having multiple meanings, if all participants in an exchange are aware of what meaning is being used in the present context. At this point, however, a final challenge appears, namely the fact that no simple and clear definition of the term "energy" exists, or to be more exact, the mathematical definition is too abstract to serve as a starting point in K-12 education (Constantinou \& Papadouris, 2012).

Students (and teachers) are thus faced with the challenge; "to learn about energy even though we have no knowledge of what energy is" (Eisenkraft, 2014). Is the struggle worth the effort? The answer made by most researchers is yes, as the concept of energy is essential for understanding both the living and the non-living world. To appreciate the broad scope of the energy concept, students need to learn about the concept in the context of physics, chemistry, biology, health science, and physical education. Only by given the opportunity to explore and recognize that the energy 
concept can be applied to both living and non-living systems, students can deepen and broaden their understanding of the concept. To quote one leading researcher "[...] the energy concept is perhaps best learnt the way we learn a new language, not through definitions, but through repeated exposure and active use" (Constantinou \& Papadouris, 2012).

The obvious next question is then how do one design learning activities that promote student learning and deepening the understanding of the energy concept? Traditional energy instruction many times involves only simple energy calculations on idealized systems, leaving the everyday, non-idealized (interesting?) systems for more advanced courses. While there is no one, unique road to a deeper understanding of such a broad concept as energy, and studying simplified systems have a clear role in any energy related course, there is also research that indicates that there is much to be gained from taking a broader, interdisciplinary approach to energy instruction (Nordine, Krajcik \& Fortus, 2011). The energy-body lab described in our case study should be understood as an effort in this direction, providing an example of what a STEM activity could look like, when organized around a central, multidisciplinary concept (energy in this case). However, due to the broad scope of the energy concept, it is also important to be clear about what aspects of the concept one as an educator wants to highlight when designing a multidisciplinary teaching-learning sequence.

In designing the energy-body lab, our focus has been on the use of the principle of conservation of energy as an analytical tool for students to understand both non-living and living (carbon-transforming) systems (Dauer, Miller \& Anderson, 2014). Our choice of placing the students' own bodies at the center of each activity is grounded in an embodied learning approach that emphasizes the use of action to support learning goals. This approach posits that the transition from action to abstraction is supported by bodily actions (Weisberg \& Newcombe, 2017). Therefore, although kinetic and potential energy, as well as work, are concepts covered in the secondary physics curriculum, our hypothesis is that by letting students encounter the energy concept via its connections with the less abstract concept of work, and involving their own bodies in the process, a deeper integration of the physical and biological aspects of the energy concept will result. 


\section{Educational setting of the study}

As stated in the national core curriculum, all students in the comprehensive school in Finland should be involved in (at least) one multidisciplinary unit during the school year (FNBE, 2016). However, the national core curriculum does not specify which subjects, or how many different subjects, should form a multidisciplinary unit, leaving this decision up to each, individual school and teachers. As mentioned earlier, the school in our study chose "Energy" as their theme for the multidisciplinary unit in grade 9. The structure of the multidisciplinary unit is shown in Figure 1. The unit was in large parts developed by the teachers involved in the implementation and consisted of two weekly 6o-minute long sessions for a total of seven weeks. All students in grade 9 participated in the unit. In spring 2017, 44 students participated in the multidisciplinary unit.

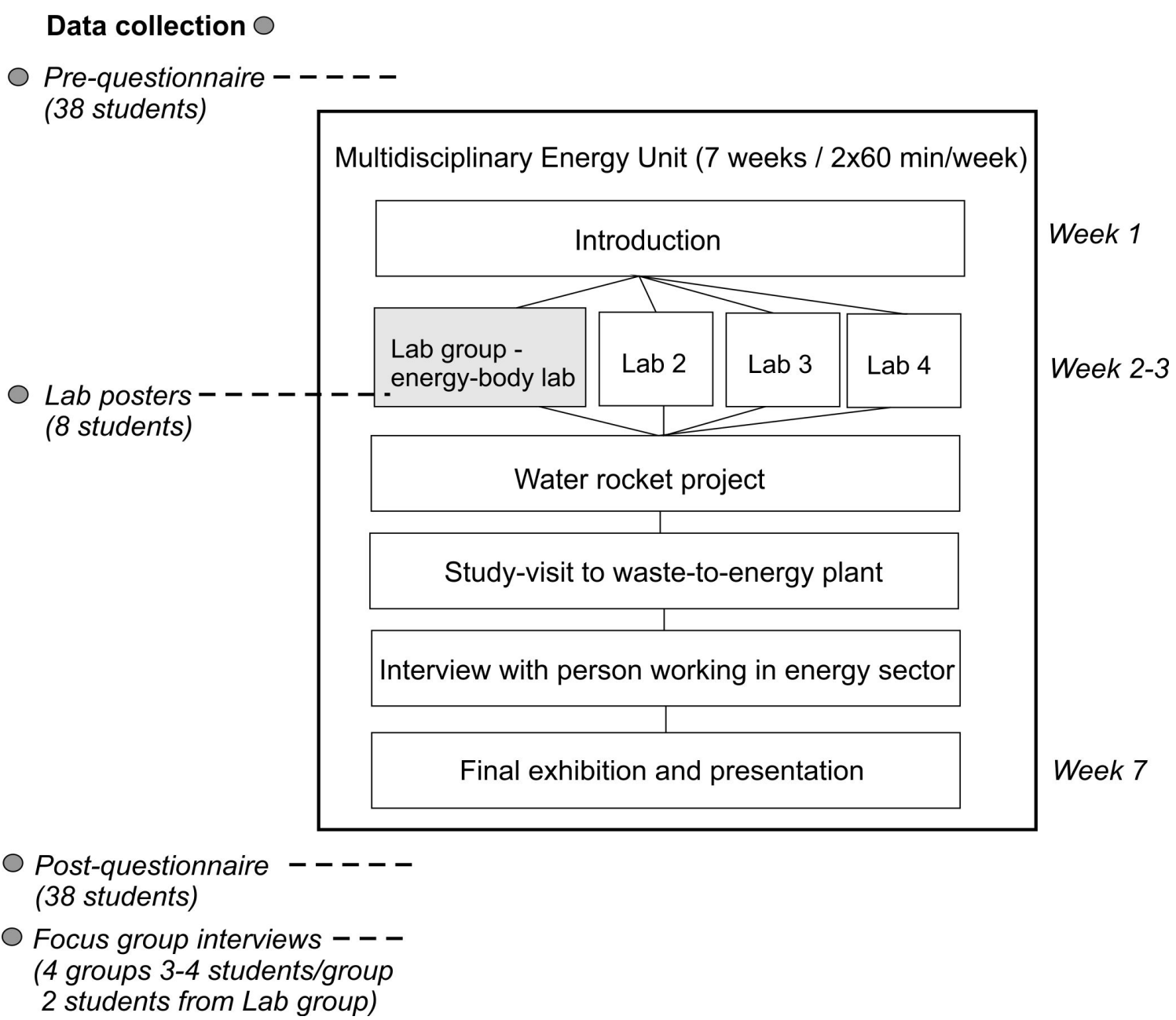

Figure 1. The structure of the multidisciplinary energy unit and timing of data collection. 
The multidisciplinary unit was divided into six parts (Figure 1). The first part consisted of a general introduction to the energy theme, followed by a set of four laboratory sessions (where the students were to choose one). In the third part, the students built and optimized their own water rocket, while the fourth part consisted of a visit to a local waste-to-energy plant. The fifth part involved conducting an interview with a non-native speaker working in the local energy sector. The whole unit ended with an exhibition, to which pupils in grade 6 were invited. For the exhibition, each group of (3-4) students planned and gave a presentation (oral, poster, or audiovisual) and interacted with the 6-th grade exhibition attendees.

The four energy-related activities that the students could choose among were: building and optimizing the blades of a model wind-power plant, building and investigating a chemical battery, exploring the photosynthesis of plants, and exploring the connections between work, energy, chemical energy and the human body (what we call here the "energy-body lab"). Eight students out of the 44 chose the energybody lab. The worksheet given to the eight students before the energy-body lab is found in Appendix A. The time reserved for the energy-body lab spanned three sessions (each 2 x 60 minutes) and all activities and measurements were done during the first session. The two following sessions were reserved for group discussions and documenting the results in the form of a poster. Both the activities, measurements and the following documentation were done in groups consisting of four students. The exact form of the poster documentation, and what each group wanted to emphasize in relation to the energy-body lab, was left up to each lab group to decide.

\section{Material and methods}

To answer the research question, and increase the validity of our results, we have used the research method of methodological triangulation (Denzin, 2006) and three ways to gather data: questionnaires, documents and student interviews. The timing of the data collection is summarized in Figure 1. The data collected in connection with the seven-week multidisciplinary energy unit, consisted of the following:

1. Two student questionnaires, one done before the start of the multidisciplinary unit and one after the unit (44 students participated in the whole unit and 38 students answered both questionnaires).

2. Poster presentations (PowerPoint) of the two student groups that participated in the energy-body lab. 
3. A set of semi-structured focus group interviews (Stewart, 2015) with a voluntary group of students (four group interviews where done, with $3-4$ students in each group). All interviews were audio-recorded and fully transcribed.

It should be noted that the persons interviewing the students where neither involved in designing the energy-body lab, nor in the actual implementation of the multidisciplinary unit. All the interviews where done after the end of the whole unit, and more than three weeks after the energy-body lab. The questions asked all student groups were the same and designed to probe their attitudes towards the multidisciplinary unit as whole. Each student group were asked about their experiences of this partly new way of working, what they saw as positive or negative with the unit and how they experienced the role of the different subjects making up the unit (physics, chemistry, biology and mathematics). Finally, they were asked if they thought they had gained a deeper understanding of the energy concept through working this way and if so, how. No questions were specifically about the energy-body lab.

For the present case study, we have selected the subgroup of eight students (of 44 students) that chose to participate in the energy-body lab. We have further focused only on the statements in the pre- and post-questionnaires that specifically relate to the multidisciplinary aspects of the energy concept (see Table 1). In answering the questionnaires, the students could choose between 5 alternatives on a Likert scale: Strongly disagree, disagree, neutral, agree and strongly agree, in response to the statements listed in Table 1 and Table 2. The alternatives are quantified from 1 (strongly disagree) to 5 (strongly agree). The four selected statements from the prequestionnaire are listed in Table 1 and labeled SI to SIV. The eight selected statements from the post-questionnaire are labeled as S1 to S8 and listed in Table 2. The eight students are coded using capital letters A to H. Before the start of the energy-body lab, the eight students were divided into two groups, group I with five students (A-E) and group II with three students (F-H). Out of the group of students interviewed after the whole unit, two students (student $\mathrm{A}$ and $\mathrm{H}$ ) also participated in the energy-body lab.

The questionnaires, the transcribed recordings of the interviews, as well as the posters produced by the students, have been analyzed to examine shifts in students' perceived importance of the energy concept and detect signs of a broadening of their energy concept after the multidisciplinary unit. In the written documents, as well as in the transcribed interviews, we have applied the selection criteria that the students should, within the same paragraph or sentence, use the term "energy" within at least 
two different contexts (for instance applying it to both living and non-living systems, i.e. their own body).

\section{Results}

The results are presented and summarized in this chapter. First, the results of the preand post-questionnaires are presented and discussed. Then, the student poster presentations are analyzed, and central quotes are extracted and highlighted. Finally, the results from the two focus group interviews (two students out of eight) are presented.

\section{Questionnaire}

A total of 44 students participated in the questionnaires, and 38 students gave complete answers (answered both the pre- and post-questionnaire). Eight of the 38 students participated in the energy-body lab. In the result presentation below, the 38 students are split into the group of 8 students that participated in the energy-body lab and the remaining 30 students. The column labeled Lab refers to the eight students participating in the energy-body lab and column Rest are the rest of the students in the multidisciplinary unit. The pre- and post-questionnaires differ, so the labelling of the selected statements between Table 1 and Table 2 differs.

Table 1. Statements selected from questionnaire before the multidisciplinary unit $(\mathrm{N}=38)$. Averages and standard deviations for statement responses are shown (AV/SD).

\begin{tabular}{llll}
\hline Label & Statement & Lab (n=8) & Rest (n=30) \\
\hline SI & All people should have knowledge of energy issues & $4,0 / 0,8$ & $3,5 / 0,9$ \\
SII & Knowledge in biology is not needed to understand energy issues & $3,8 / 1,2$ & $3,6 / 0,9$ \\
SIII & Knowledge in chemistry is not needed to understand energy issues & $4,4 / 1,1$ & $3,7 / 1,0$ \\
SIV & I want to learn more about future energy sources & $4,4 / 0,5$ & $3,1 / 1,1$ \\
\hline
\end{tabular}

The average and standard deviation for the response on each statement in the prequestionnaire is listed in Table 1, where the response values for the negated statements SII and SIII have been reversed. The eight students from the Lab group scored higher on all statements than the rest of the students. Due to the small sample size of the Lab group and non-normal distributions, no significance test is conducted. 
On average, students agree that knowledge of energy issues are important and that they want to learn more about future energy sources. They also recognize that knowledge in biology and chemistry is needed to understand energy issues.

The average and standard deviation for the response on each statement in the post-questionnaire is listed in Table 2. Due to the small sample size of the Lab group and non-normal distributions, no significance test is conducted.

It should be noted that all students $(\mathrm{N}=38)$ participating in the multidisciplinary unit have had the energy concept as a part of their regular physics courses (i.e., heat, kinetic and potential energy), therefore energy is usually connected to physics in the minds of many students.

Table 2. Statements selected from questionnaire after the multidisciplinary unit $(N=38)$. Averages and standard deviations for statement responses are shown (AV/SD).

\begin{tabular}{llll}
\hline Label & Statement & Lab $(\mathbf{n}=\mathbf{8})$ & Rest $(\mathbf{n}=\mathbf{3 0})$ \\
\hline S1 & Mathematics is needed to work on energy issues & $4,1 / 0,6$ & $3,7 / 1,0$ \\
S2 & Knowledge of physics is needed when working with energy issues & $4,8 / 0,5$ & $4,2 / 0,8$ \\
S3 & Knowledge of chemistry is needed when working with energy issues & $4,1 / 1,1$ & $4,0 / 0,7$ \\
S4 & Knowledge in biology is needed when working with energy issues & $3,8 / 0,9$ & $3,7 / 1,0$ \\
S5 & All people should have knowledge of energy issues & $4,5 / 0,9$ & $3,6 / 1,0$ \\
S6 & $\begin{array}{l}\text { The multidisciplinary unit has given me a greater understanding of } \\
\text { how energy is produced }\end{array}$ & $4,0 / 1,4$ & $3,6 / 1,3$ \\
S7 & $\begin{array}{l}\text { The multidisciplinary unit has given me a greater understanding of } \\
\text { the body's energy consumption }\end{array}$ & $3,1 / 1,2$ & $2,6 / 1,1$ \\
S8 & $\begin{array}{l}\text { The multidisciplinary unit has shown me that different school } \\
\text { Subjects are needed to better understand energy issues }\end{array}$ & $3,1 / 1,6$ & $3,3 / 1,0$ \\
\hline
\end{tabular}

The eight student responses to the selected statements from questionnaire after the multidisciplinary unit are shown in Figure 2. The average response for the eight students and the rest of the students are also visualized. The blue shaded columns in Figure 2 refers to the five students (A-E) that constituted Lab group I and the brown shaded bars correspond to the three students (F-H) in Lab group II. Student E did not respond to statement $\mathrm{S}_{3}$. Statements $\mathrm{S}_{1}$ to $\mathrm{S}_{4}$ are all related to if students agree that different subjects (mathematics, physics, chemistry and biology) are needed for the understanding of energy issues. Most students, both in the Lab group and overall, agree that knowledge of different subjects is needed in order to understand energy issues. Most students also agree with the statement that all people should have knowledge of energy issues ( $\mathrm{S}_{5}$ ) and the multidisciplinary unit had given them a greater understanding of how energy is produced (S6). 
One of the specific goals of the energy-body lab was to illuminate the use of energy concept to understand the connections between food, oxygen and bodily work. Although, despite the slightly higher average score for the Lab group on statement S7, they did not agree that the multidisciplinary unit had given them a much greater understanding of the body's energy consumption. They also remained neutral to the statement that the multidisciplinary unit had showed them that different school subjects are needed to better understand energy issues (S8).

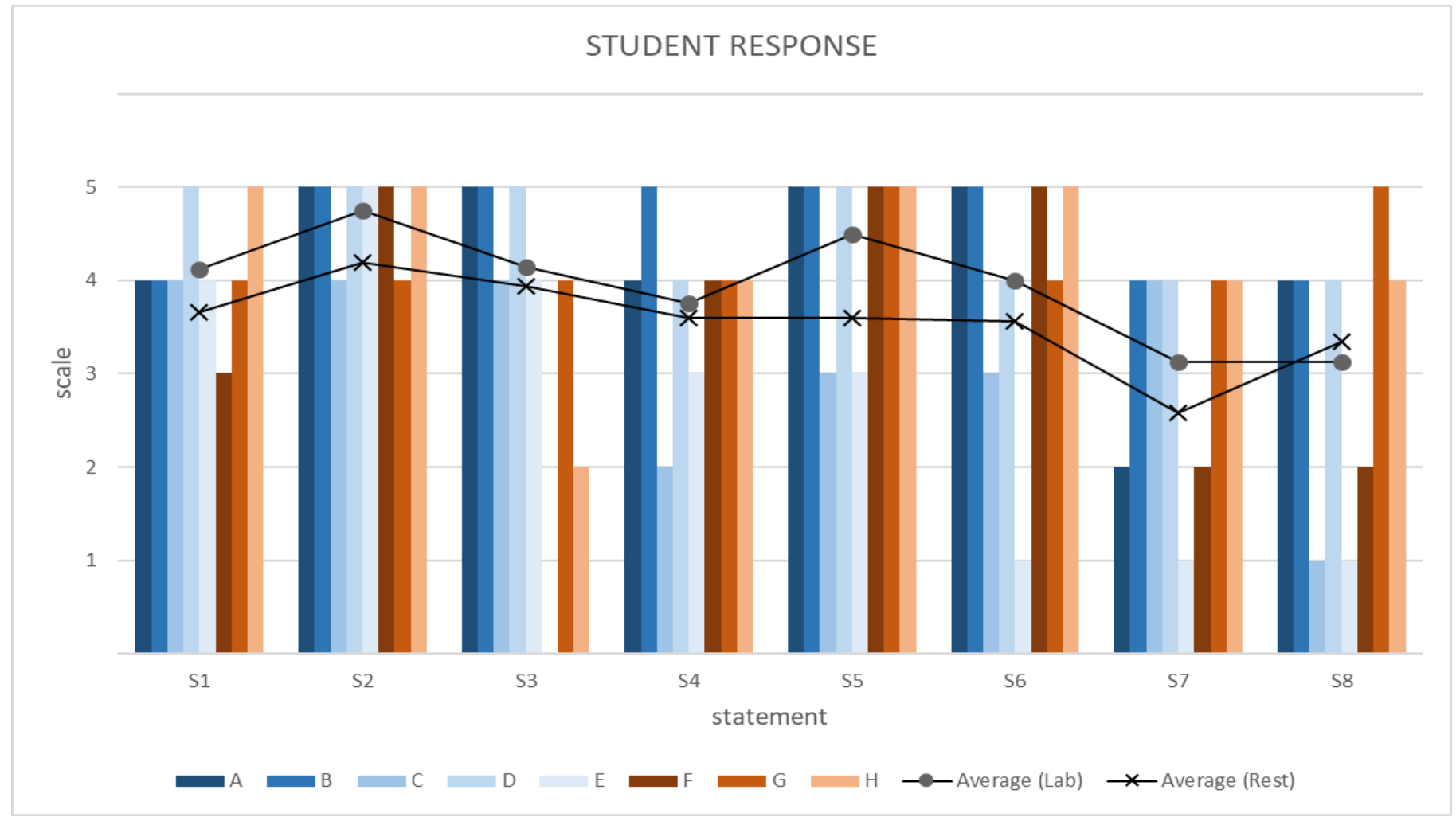

Figure 2. Student response to selected statements in the post-questionnaire.

\section{Poster excerpts}

Eight students participated in the energy-body lab. Each of the two lab groups produced a poster as their lab report after the activity (Appendix A). Excerpts directly related to the research question where identified and are reproduced (translated to English) below. The criteria for our selection were that at least two different aspects and uses of the energy concept should be visible in the text. This selection criterion is used as a visible sign of students' understanding of the multidisciplinary character of the energy concept. 
Our leg muscles converted first the chemical energy to kinetic energy. With the kinetic energy we moved up on the bench. (Lab group I, excerpt 1, activity 2)

This excerpt highlights chemical energy conversion by muscles to movement (kinetic energy).

Then you get the amount of energy that has been 'used' during this period. Some of us used almost as much energy as a light bulb during the lab. So in -other words, we used quite a lot of energy during a short time. (Lab group I, excerpt 2, activity 2)

[...] but then again much closer to the light bulb, as it is not likely that you can do work as the same pace as a kettle, which reaches a relatively high temperature. (Lab group II, excerpt 1, activity 2)

The body's energy conversion is also highlighted in these two excerpts. However, in this case the energy conversion rate is compared to that of inanimate objects (light bulb and a kettle).

But with 1 kilojoule, you could theoretically lift an apple (ca $100 \mathrm{~g}$ ) 1000 meters up in the air or two apples to the top of the Eiffel tower. (Lab group I, excerpt 3, activity 2)

This excerpt compares the total energy used by the body in the activity with the potential energy gained by lifting an inanimate object (an apple) to a certain height.

We measured the body's outer temperature both before and after the workout to see how it changed and also thought about why these changes happened.

Regarding our body temperatures, the most natural explanation was that it went up as we exerted ourselves and sweated. This is the conclusion that the majority probably would draw as you get incredibly warm during hard exercise. (Lab group II, excerpt 2, activity 2)

This excerpt states that a result of bodily work results in an increase of body temperature and sweating; kinetic energy is converted into heat.

That the oxygen level should go down and the carbon dioxide up was the most likely hypothesis we had before doing the actual experiment and sure enough it did! This because the body during physical exertion needs more oxygen and so the body also gets rid of larger amounts of carbon dioxide than usual. (Lab group II, excerpt 3, activity 3) 
This final excerpt highlights the bodily response to physical exertion; the body needs more oxygen to handle increased physical movement, resulting in more carbon dioxide being produced.

\section{Interview excerpts}

In this section results from the two focus group interviews are presented. Many things were discussed during the interviews, such as student motivation, working methods, etc. We have only included excerpts directly related to the multidisciplinary aspects of energy. Two of the eight students (student A and H) participated in the interview. Excerpts from the interview connected to the research question are listed below.

[...] energy is like hugely important in the future [...] like this with nonrenewable and renewable energy sources $[. .$.$] because we will be affected by all$ oil running out, so we should get like more knowledge about these things. (Student A)

[...] so energy is not only about physics, not only about chemistry, it is not focused on only one subject, but on them all cooperating. (Student A)

Student A states that a thorough understanding of the energy concept is important for a sustainable future and also that this knowledge is a result of the cooperation of several different subjects.

[...] and then you could vary. Now it was about these science subjects, especially chemistry, maths and physics. That for instance subjects like history, geography and languages and such got completely left out. [...] Yes, you could have done the history of energy. (Student H)

Yes but it was also that we worked with energy in physics while we were doing the multidisciplinary unit, so it built upon talking about kinetic energy in the unit, then we started with it in physics and that supported each other so it helped quite a bit. (Fellow student together with student $\mathrm{H}$ )

Student $\mathrm{H}$ reflects on the lack of other possible subjects in the multidisciplinary unit; in this case the historical aspect of energy development. The student also makes connections to the content of "ordinary" physics lessons and it clearly supported the ambitions of the multidisciplinary unit. 


\section{Summary of results}

All students were initially relatively positive to the multidisciplinary unit (prequestionnaire). The group of the eight energy-body lab students were above average on most statements, both in the pre- and post-questionnaire (on 11 out of 12). They were well motivated and saw the relevance of an interdisciplinary approach to better understand energy. The two student groups could freely choose what to document in their poster presentations. In the documentation of activity 2 and 3 , the students were able to make connections between different aspects of energy; i.e. living and nonliving systems. However, activity 1 proved to be too challenging for both groups. The written documentation on activity 1 contained several errors and the documentation showed a lack of deeper insights. The interview highlighted that the students realized that a thorough understanding of the energy concept needs the cooperation of different subjects.

\section{Discussion and conclusions}

The question of what exactly a multidisciplinary STEM unit should be in a school context, and what the roles of the individual school subjects should be within that unit, is the natural starting point before planning such a unit (cf. McPhail, 2018). Although, having several subjects, and thus several teachers, cooperate around a theme or a problem, has been advocated by some researchers (e.g. Brand \& Triplett, 2012), it can also become very time consuming for the teachers involved (Braskén et al., 2019). It takes time to identify themes and develop criteria for the assessment of those themes, especially if a theme requires a multidisciplinary approach and, as is often the case, no existing teaching material emphasizing this approach is available to support the teachers (for an overview of various interdisciplinary science efforts, see Czerniak \& Johnson (2014)).

One approach, and the one chosen by the teachers in our study, is to organize a multidisciplinary STEM unit around a so called crosscutting concept (NRC, 2012). By letting an interdisciplinary, crosscutting concept become the organizing element of a unit, much of the hard work of integrating various subjects into a meaningful whole is eased. However, due to the (by definition) very broad scope of such a concept, one needs to focus and emphasize only on certain aspects of a concept at any given time. There is also a tension in the order that various supporting concepts should be thought. In our case study, the students had encountered the concepts of work, kinetic 
and potential energy in their physics class, before they participated in the energy-body lab. It could be convincingly argued that trying to introduce several new concepts, at the same time as trying to facilitate students to forge interdisciplinary connections between these concepts, would result in an excessive cognitive load and thus minimal learning (Sweller, 1988). We can partly see this in the students' poster discussions relating to activity 1 (see Appendix A). This activity combined the concepts of force, work, potential energy and kinetic energy. Although the activity and measurements were made without difficulties, the students' poster documentation clearly shows that not even the most able student groups were able to bring all these concepts together to form a meaningful whole. No poster quotes, nor interview excerpts, relating to activity 1 could be identified that shows any signs of a deepened understanding of the multidisciplinary character of the energy concept.

This problematic activity 1 should be contrasted with activities 2 and 3, which contained fever calculations and seemingly fever challenging concepts. The poster quotes connected to these two activities are richer and deeper. In the quotes connected to activity 2 , the students discuss and compare the energy conversion rate of a lightbulb with the energy conversion of their own body. The students also make the connection between energy being lost in the conversion and ending up as heat, i.e. an increase in body temperature. Thus, the students are able to use the energy concept to compare physical and biological systems, revealing an understanding of the multidisciplinary character of energy and work.

Based on the poster documentation related to activity 3, this was a more challenging activity than activity 2. Only one of the two groups showed a deeper understanding of the energy conversions involved, from chemical energy stored in the muscles to the carbon dioxide produced and measured, which was one of the main goals of the energy-body lab. Connecting to our research question, this shows the challenges of developing activities that promote a unified understanding of a complex concept, such as energy.

The student posters were all written as part of the energy-body activity, and the worksheets given to the students before the lab contained both scaffolding and leading questions pointing in the desired direction. However, both the post-questionnaire and the student focus group interviews were done several weeks after the energy-body lab. The general, open-ended interview questions served as initial conversation starters and were not intended to probe the energy-body activity or the different aspects of the energy concept. The multidisciplinary character of the energy concept is clearly visible 
and present in the interview excerpts. But, the students do not spontaneously bring up the connections between energy used to describe living and non-living systems. The results of the pre-questionnaire shows that the eight energy-body lab students were well aware of energy being an important and a multidisciplinary concept (SISIII), and that they especially wanted to know more about future energy sources. The post-questionnaire shows that they still agree with the statements that energy is a multidisciplinary concept and that it is important to have knowledge about it ( $\mathrm{S} 1-\mathrm{S} 4)$. However, their response to statement S7 shows that they did not consider the multidisciplinary unit had given them a greater understanding of the body's energy use. The individual variation in the response to statement $\mathrm{S}_{7}$ is especially large, suggesting that the energy-body lab was perhaps too difficult for some students. The low score on statement S8 also indicates that bringing different subjects together in a multidisciplinary unit, does not automatically enhance the students' understanding of energy.

Designing an integrated STEM activity can be a challenging task. One way to reduce the challenge is to build the activity around a crosscutting concept, which in our case study was energy. Due to the broadness of a crosscutting concept, it is necessary to focus on a few well-defined aspects of the concept, which in our case was to relate the use of energy to describe changes in both living and non-living systems. It is very important to be clear on which concepts are assumed familiar to the students and which concepts are to be learned and deepened in the activity. It is not realistic to assume that individual teachers nor schools can (or have the time to) develop high quality, integrated STEM material, without professional support. Therefore, one way forward is to systematically develop, test and make available research-based material for interesting and challenging STEM activities for different grades.

\section{Acknowledgements}

The research project that this paper is based on is financed by Högskolestiftelsen i Österbotten.

\section{References}

Brand, B. R., \& Triplett, C. F. (2011). Interdisciplinary curriculum: An abandoned concept? Teachers and Teaching. Theory and Practice, 18(3), 381-393.

https://doi.org/10.1080/13540602.2012.629847 
Braskén, M., Hemmi, K. \& Kurtén, B. (2019). Implementing a Multidisciplinary Curriculum in a Finnish Lower Secondary School - The Perspective of Science and Mathematics.

Scandinavian Journal of Educational Research, 64(3), 852-868. London: Taylor \& Francis https://doi.org/10.1080/00313831.2019.1623311

Czerniak, C. M., \& Johnson, C. C. (2014). Interdisciplinary science teaching. In N. G. Lederman \& S. A. Abell (Eds.), Handbook of research on science education (Vol. 2, pp. 395-411). New York, NY: Routledge.

Constantinou, C. P., \& Papadouris, N. (2012). Teaching and learning about energy in middle school: an argument for an epistemic approach, Studies in Science Education. 48, 161-186. London: Taylor \& Francis. https://doi.org/10.1080/03057267.2012.726528

Dauer, J., H. K. Miller, \& Anderson, C. W. (2014). Conservation of Energy: An Analytical Tool for Student Accounts of Carbon-Transforming Processes. In R. F. Chen, A. Eisenkraft, D. Fortus, J. S. Krajcik, K. Neumann, J. C. Nordine \& A. Scheff (Eds.), Teaching and learning of energy in K-12 education (pp. 67-85). New York: Springer.

Denzin, N. (2006). Sociological Methods: A Sourcebook. Aldine Transaction. (5th edition).

Duit, R. (2014). Teaching and learning the physics energy concept. In R. F. Chen, A. Eisenkraft, D. Fortus, J. S. Krajcik, K. Neumann, J. C. Nordine \& A. Scheff (Eds.), Teaching and learning of energy in K-12 education (pp. 67-85). New York: Springer.

Eisenkraft, A. (2016). Teaching about energy as a crosscutting concept. In J. Nordine (Ed.), Teaching energy across the sciences K-12, (pp. 39-57). Arlington, VA: NSTApress

Finnish National Board of Education. (2016). National core curriculum for basic education 2014. Helsinki, Finland: Next Print Oy.

McPhail, G. (2018). Curriculum integration in the senior secondary school: A case study in a national assessment context. Journal of Curriculum Studies, 5(1), 56-76.

https://doi.org/ 10.1080/00220272.2017.138623

Millar, R. (2005). Teaching about energy (Research Paper 2005/11), York: Department of Educational Studies, University of York. Retrieved July 15, 2020, from www.york.ac.uk/education/research/research-paper.

National Research Council (2012). A framework for K-12 science education: Practices, crosscutting concepts, and core ideas. Washington, DC. National Academies Press.

Nordine, J. Krajcik, J., \& Fortus, D. (2011). Transforming energy instruction in middle school to support integrated understanding and future learning. Science Education, 95 (4), 670-699. New York: Wiley. https://doi.org/10.1002/sce.20423

Nordine, J. (2016). Why is energy important? In J. Nordine (Ed.), Teaching energy across the sciences $K-12$, (pp. 3-15). Arlington, VA: NSTApress

Stewart, D.W., \& Shamdasani, P. N. (2015). Focus Groups: Theory and Practice. Thousand Oaks: SAGE Publications, Inc. (3rd edition)

Sweller, J. (1988). Cognitive Load During Problem Solving: Effects on Learning. Cognitive Science. 12 (2), 257-285.

https://doi.org/10.1207/s15516709cog1202_4

Voogt, J., \& Roblin, N. P. (2012). A comparative analysis of international frameworks for 21st century competences: Implications for national curriculum policies. Journal of Curriculum Studies, 44(3), 299-321.

https://doi.org/10.1080/00220272.2012.668938

Weisberg, S. M., \& Newcombe, N. (2017). Embodied cognition and STEM learning: overview of a topical collection in CR:PI. Cognitive Research: Principles and Implications, 2(38)

https://doi.org/10.1186/s41235-017-0071-6 


\section{Appendix A: ENERGY-LAB WORKSHEET}

\section{Activity 1. JUMP! HOW MUCH DO YOUR LEG MUSCLES HAVE TO WORK?}

When you lift a heavy box, you can calculate the work you do by measuring how high you lift the box (= the distance) and how much force you use. As you climb the stairs, your leg muscles must

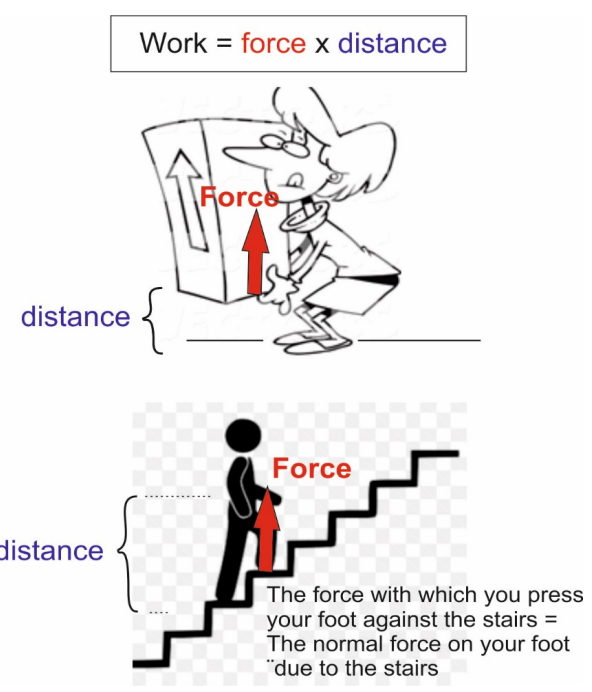

\section{Lab} work to lift your entire body upwards, which is why climbing stairs is so heavy. Your leg muscles also need to work when you jump with both feet together. You investigate these things in this lab.

In this lab, you will investigate how much force the leg muscles develop when you jump straight up with both feet together. You have a force plate to measure the force of take-off and a measuring tape to measure the height of the jump. Feel free to video record the entire jump with the measuring tape in the background. To calculate the work done by the leg muscles you have to measure the distance from the start of the jump (bent knees) to the point when the legs are completely straight (see picture below).

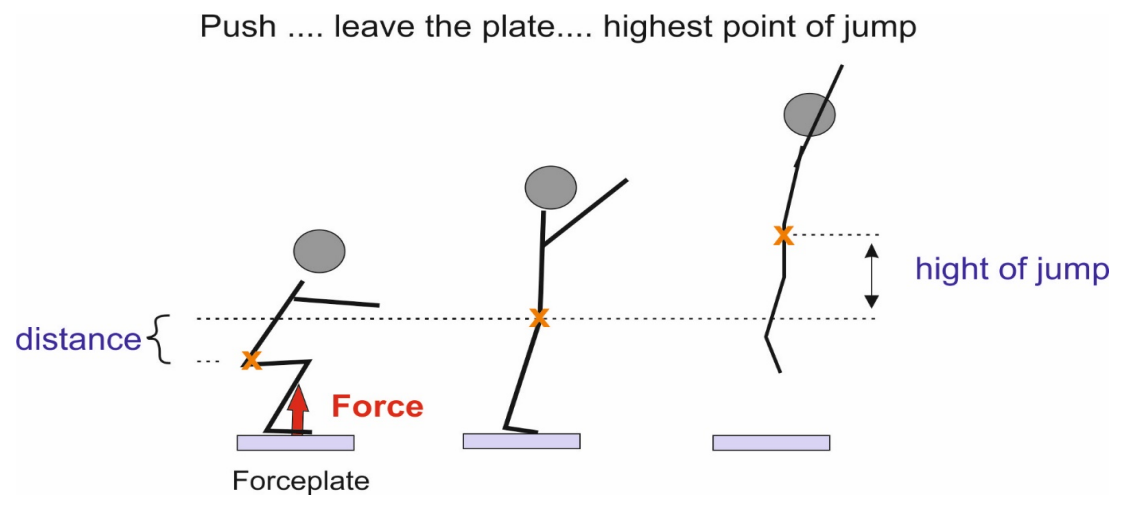

Analyze your measurement results and video clip and write down the results in the table below.

\begin{tabular}{|c|c|c|c|}
\hline $\begin{array}{c}\text { Maximum force } \\
\text { during take-off } \\
\text { (Newton) }\end{array}$ & $\begin{array}{c}\text { Average force } \\
\text { during take-off } \\
\text { (Newton) }\end{array}$ & $\begin{array}{c}\text { The distance from } \\
\text { bent to straight legs } \\
* \text { (meter) }\end{array}$ & $\begin{array}{c}\text { The height of the } \\
\text { jump (meter) }\end{array}$ \\
\hline & & & \\
\hline
\end{tabular}

* To measure the distance and the height of the jump, you must follow the same point on the body. The easiest way is to follow how the hip joint moves, for example by attaching a clearly visible piece of tape to the hip 


\section{Questions and calculations}

How much work do your leg muscles do? (The unit for work is joule)

The work, calculated above, that your leg muscles do is used to give your body a certain initial speed. The height of the jump depends on the magnitude of the initial speed. Calculate the height $(h)$ of jump when you know the work and the mass $(m)$ of your body *

Calculated height of jump $=$ $\mathrm{m}$

Measured height of jump = $\mathrm{m}$

Did the calculated height agree with the measured height? If not, what could be the reason/cause?

Think about what you can do to jump higher. Suggestions:

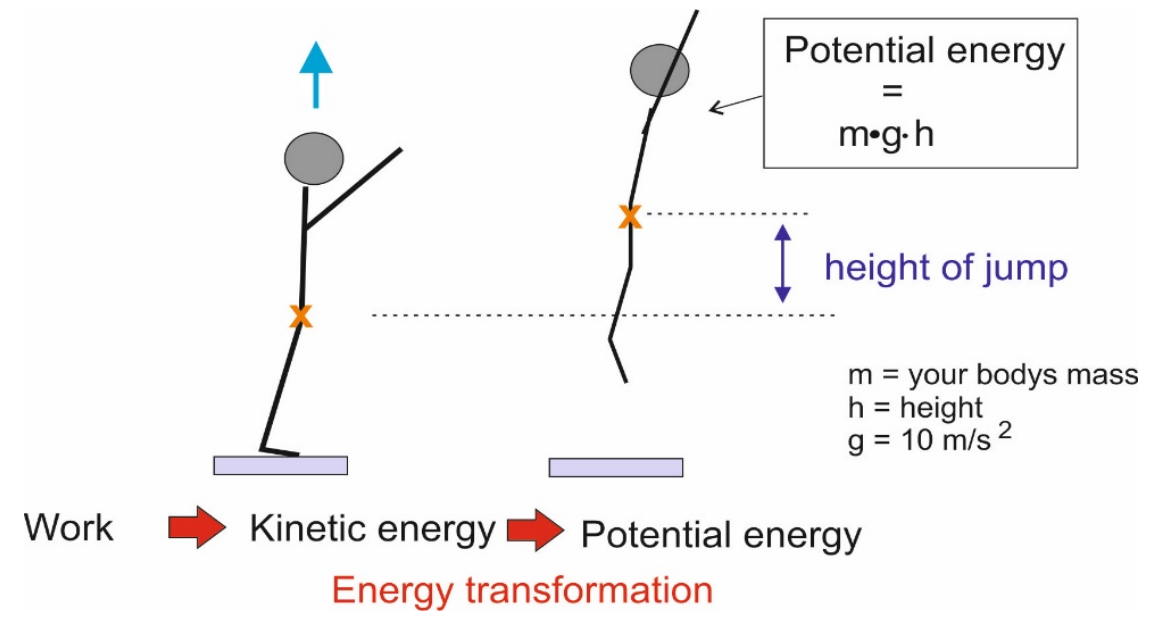

* The law of conservation of energy states that the work done by your leg muscles = the potential energy of your body when it is at its highest point (see picture above). 


\section{Activity 2. HOW EFFICIENT ARE YOU?}

Doing a job requires energy. To compare different types of work, it is not enough just to look at the amount of energy required. We must also need to look at how long it takes to do the work. You already know this because you know that there is a big difference between working fast (high power) or working slowly (low power).

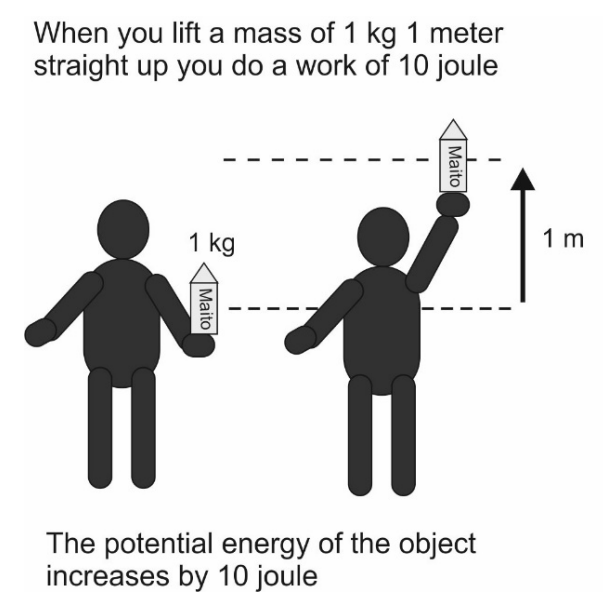

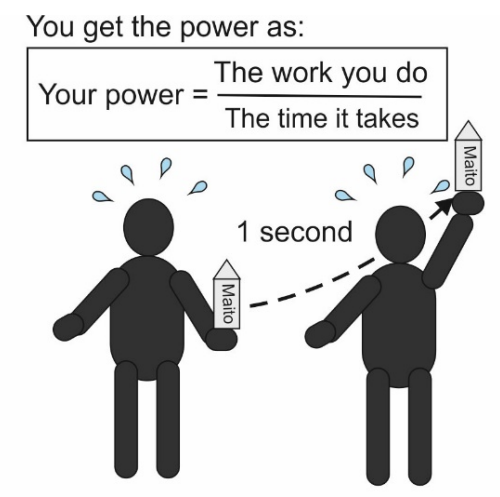

If it takes 1 second to lift $1 \mathrm{~kg}$ to a height of 1 meter, then your power is $=10$ watt

\section{Lab}

In this lab you will investigate the power your body develops when you as quickly as possible, climb/step up and down on a bench. For your help you have a tape measure and a watch. Measure how high your body is lifted when you climb/step up on the bench. Decide how many times you should climb/step up and down the

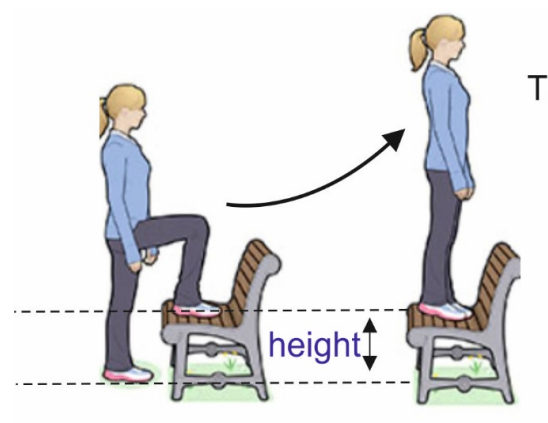

The work you do $\mathrm{m} \cdot \mathrm{g} \cdot \mathrm{h}$

$\mathrm{m}=$ your mass $\mathrm{h}=$ height $\mathrm{g}=10 \mathrm{~m} / \mathrm{s}^{2}$ bench (at least 30). Measure the temperature of your skin (e.g. at the neck) before and after the workout. Measure the time it takes to complete the workout and record your results in the table below.

\begin{tabular}{|l|l|l|l|}
\hline Height of step (meter) & Number of steps & Time (seconds) & Total work (joule) \\
\hline & & & \\
\hline
\end{tabular}

Skin temperature before $=$ ${ }^{0} \mathrm{C}$ ${ }^{0} \mathrm{C}$ 


\section{Questions and calculations}

My power was = watt

What is a typical (electrical) power of a light bulb and a kettle?

How large is your measured power compared to the power of these electrical devices?

Does the temperature of your skin change with effort? In what way?

The energy you used to do the work you just did comes from the chemical energy of the glycogen stored in your muscles *. Can you use all the chemical energy stored in the glycogen to do work? If not, where does the rest of the chemical energy end up?

* To quickly increase the amount of glycogen you can e.g. eat carbohydrates (= sugar) 


\section{Activity 3. FROM WHERE DO YOU GET YOUR ENERGY?}

Energy is needed to do work and to keep you alive. You get the energy from the food you eat (carbohydrates, proteins and fat). The chemical energy from the food can be stored as glycogen (fast energy) or as fat (slower). The process that energizes your muscles to do their job is called cell respiration and that is the process of the oxygen in the air you breathe in + glucose (sugar) that turns into energy, with carbon dioxide and water as residual products (see picture to the right).

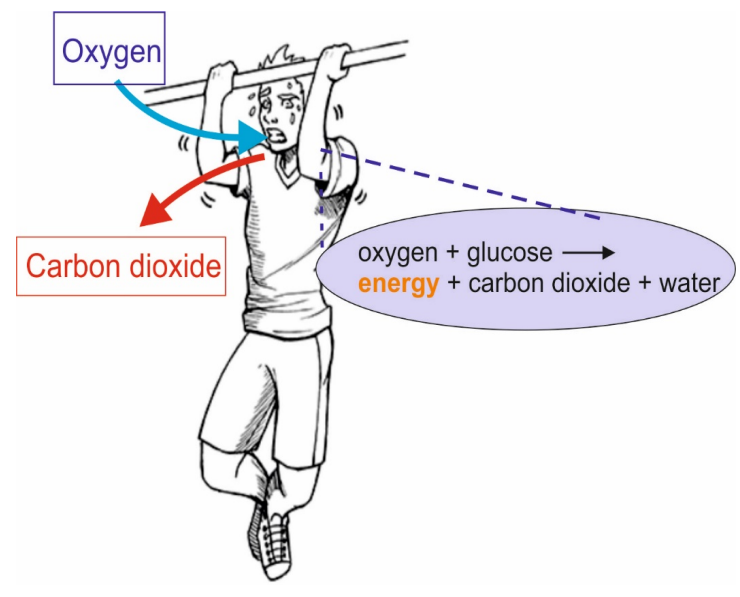

\section{Lab}

1. Start by measuring how much oxygen and carbon dioxide there is in the classroom.

Oxygen (O2) $\%$

Carbon dioxide $(\mathrm{CO} 2)$ ppm *

* The proportion of carbon dioxide is so small in the atmosphere that it is stated in the unit ppm (parts per million ie millions of parts). The relationship is $1 \mathrm{ppm}=0.001$ promille $=0.000001$ percent .

a) Insert the carbon dioxide and oxygen meter into a 2 liter sealable plastic bag. Also, insert a straw into the plastic bag so you can inflate the bag using your exhaled air (see picture). Exhale through the straw to fill the plastic bag. Measure and record the amount of oxygen and carbon dioxide in your exhaled air.

b) Make a new plastic bag similar to the first one. Increase your heart rate by jumping, running, ... for at least 5

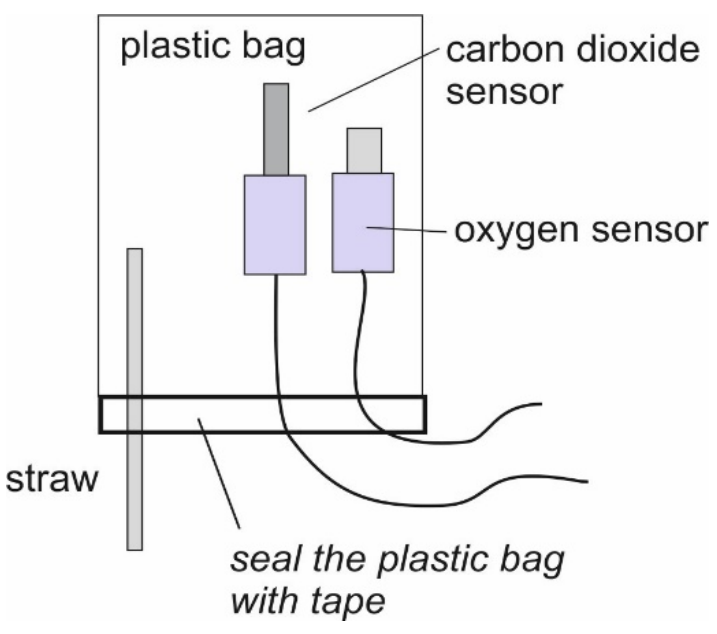
minutes. Again measure the amount of oxygen and carbon dioxide in your exhaled air.

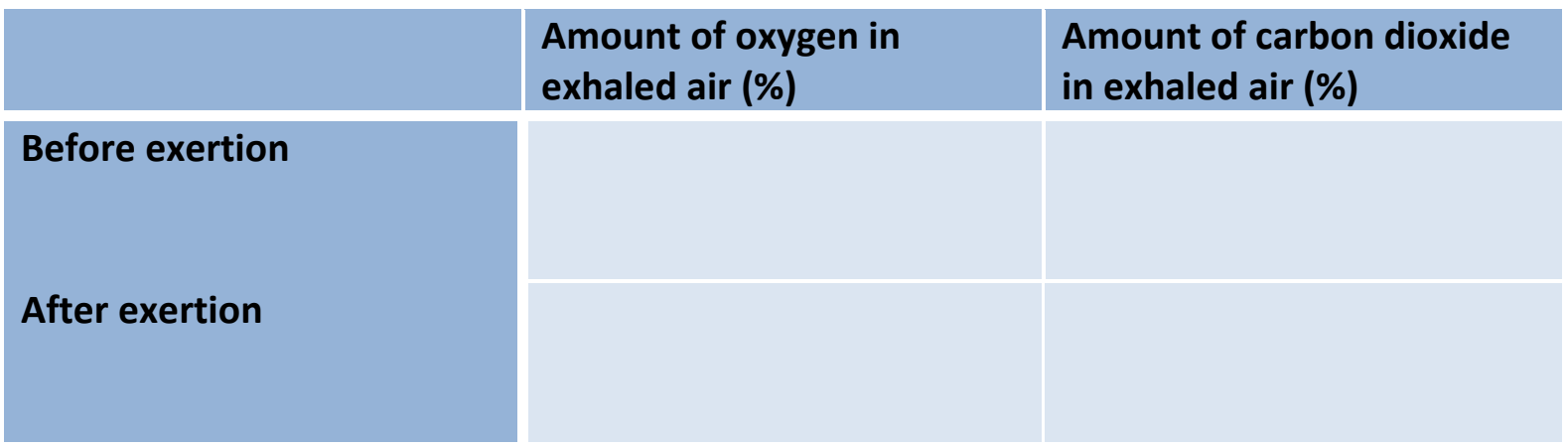




\section{Questions}

Was there any difference in the amount of oxygen and carbon dioxide in the exhaled air before and after exertion?

Can you, with the help of how the body convert the chemical energy of glucose into energy, explain the results you obtained?

Do you think there will be any difference in the results if you have good or bad fitness/condition? In what way, if so? 